\title{
“De farinha, bendito seja Deus, estamos por agora muito bem": uma história da mandioca em perspectiva atlântica
}

\author{
"Of flour, blessed be God, now we are very well": \\ A History of manioc in Atlantic perspective
}

Jaime Rodrigues*

\section{Resumo}

$\mathrm{O}$ artigo faz um inventário de referências à mandioca a partir da crônica colonial, da literatura de viagem e da correspondência administrativa, buscando analisar as formas do conhecimento indígena envolvidas no plantio da mandioca e na produção da farinha. Mediante a apropriação desses saberes e constatada a durabilidade do produto, estuda-se a importância transatlântica da planta e da farinha de mandioca para o sustento de africanos, escravos em trânsito pelo Atlântico, marinheiros em circulação pelo mundo a partir da era das navegações europeias e mesmo para o suprimento de demandas do Reino de Portugal. A intenção é ultrapassar fronteiras políticas, culturais e linguísticas, demonstrando como o saber dos indígenas foi parte fundante da história atlântica, mesmo que a circulação geográfica desses homens e mulheres pelos mares fosse restrita.

Palavras-chave: história indígena; história da alimentação; história marítima.

\section{Abstract}

This article does an inventory of references about the manioc starting from the colonial chronic, the travel literature and the administrative correspondence, aiming to analyze the forms of the indigenous knowledge related to the manioc planting and the flour production. With the appropriation of that knowledge and verification of the product's durability, I analyze the transatlantic importance of the plant and of the manioc flour to the Africans sustenance, slaves traveling across the Atlantic, and sailors in circulation around the world in the era of European navigations and even to the supply of the Portugal Kingdom's demands. The intention is go beyond the political, cultural and linguistic borders, demonstrating how the indigenous knowledge was a fundamental part of the Atlantic History, despite the restricted geographic circulation of that men and women in the seas.

Keywords: Indigenous History; History of food; maritime History.

\footnotetext{
* Departamento e Programa de Pós-Graduação em História, Escola de Filosofia, Letras e Ciências Humanas (EFLCH), Universidade Federal de São Paulo (Unifesp). Guarulhos, SP, Brasil. rodrigues jaime@gmail.com
} 
Pelas qualidades nutritivas da farinha, adaptabilidade da sua cultura a qualquer terreno e excepcional rusticidade, a mandioca, introduzida pela tradição indígena, foi universalmente adotada pela colonização como gênero básico de alimentação; e assim se perpetuou até nossos dias. É certamente a maior contribuição que nos trouxe a cultura indígena.

(Prado Jr., 1986, p.165-166) ${ }^{1}$

Comida de índios selvagens e de escravos negros no Brasil, acabou por fazer a viagem inversa, e ir alimentar em África os pais dos futuros escravos que a comeriam na sua América de origem. As datas fogem-nos nesses mundos onde impera a transmissão oral, com referências cronológicas as mais das vezes impossiveis de reduzir a uma datação absoluta.

(Rocha, 1998, p.38)

Os derivados da estévia são comercializados como uma alternativa ao açúcar de cana, aguçando o interesse de empresas transnacionais fabricantes de refrigerantes e alimentos. A percepção do teor adoçante da planta, nativa da América do Sul, pertence ao universo de saberes dos Guarani, que a chamam de $\mathrm{Ka}^{\prime} \mathrm{a} \mathrm{He}^{\prime} e$. As comunidades dessa etnia exigem hoje direitos de propriedade intelectual pelos conhecimentos que detêm a esse respeito. ${ }^{2}$ Em 2013, após anos enfrentando os Ashaninkas do Acre na Justiça, uma grande empresa foi inocentada da acusação de biopirataria pelo uso do murumuru na fabricação de seus produtos. A justiça brasileira entendeu que "o uso da planta para fins cosméticos [ocorre] desde 1927 ... [e que] 'qualquer pessoa' poderia desenvolver produtos com o murumuru". ${ }^{3}$

Histórias como essas, ocorridas no passado recente, dialogam com a Convenção sobre Diversidade Biológica, de 1992, ${ }^{4}$ e o Protocolo de Nagoya, assinado em 2010 e em vigor desde 2014, pelo qual foram acordadas diretrizes de comércio entre o país provedor de recursos genéticos e o que irá utilizá-los com fins comerciais.

Embora recente e documentada pela imprensa, a apropriação de saberes indígenas sem o reconhecimento de seus direitos é comum e dialoga com o passado mais remoto. Talvez o caso mais antigo seja o da mandioca e da farinha produzida a partir dela, apropriadas pelos europeus desde o século XVI. 
Sem pretender esgotar o assunto, farei aqui uma espécie de inventário das referências à mandioca, ao conhecimento indígena envolvido na produção da farinha e à importância transatlântica do produto no sustento das gentes em circulação por diferentes partes do mundo a partir da era das navegações europeias (Rodrigues, 2016, p.88-91; Rodrigues, 2013, p.342-346).

O trânsito alimentar intercontinental tem atraído maior atenção dos historiadores ao menos desde a década de 1970 e do estudo clássico de Alfred Crosby Jr. (1972). No texto que ora apresento, o interesse recaiu sobre essas trocas como experiência global, concentrado na mandioca, vegetal que durante milênios foi domesticado pelos índios da América do Sul. A apropriação do saber indígena representou um ganho para os conquistadores europeus, garantindo a fixação no continente e as calorias necessárias às viagens de longa distância, viabilizando o tráfico de africanos ao ser incorporado às rações de marinheiros e escravos em ambos os lados do Atlântico e na travessia, bem como na dieta de africanos em seu próprio continente. O trânsito do vegetal e da farinha dele derivada incorporou os indígenas da América aos circuitos comerciais atlânticos, mesmo quando eles não estavam ali fisicamente.

Para Sérgio Buarque de Holanda, a farinha de milho era a preferida dos colonos de São Paulo, tanto em razão de a planta "se ajustar melhor ... aos hábitos peculiares à gente de serra acima" como pela produção em maior escala se comparada à da mandioca. Caio Prado Jr. relativizou a afirmação, também presente em Capistrano de Abreu, sobre a preferência do milho em relação à mandioca no sul da colônia: para ele não se tratava apenas das condições naturais tais como a existência de água corrente necessária ao cultivo, havia também "o maior emprego, nas montanhosas regiões do Sul, de bestas de carga cuja alimentação essencial é o milho”. O gosto e o hábito alimentar também eram motivos importantes: "mais de um viajante da primeira metade do século [XIX] ... ainda se refere à aversão constante que tinham os velhos paulistas pela farinha de mandioca, considerada menos nutritiva, embora de mais fácil digestão, do que a de milho. Spix e Martius escreviam dos moradores de São Paulo, em 1818, que consideravam a mandioca alimento pouco sadio..." (Holanda, 1975, p.222-223) (Prado Jr., 1986, p.166; Panegassi, 2009, p.398). Embora o assunto tenha motivado certo debate sobre a composição das dietas entre as diferentes áreas da colônia, o fato é que também a cultura e os usos do milho faziam parte dos saberes indígenas sobre a domesticação dos alimentos, sendo isso tão relevante quanto as diferenças de hábito alimentar entre os colonos. 
Ao longo do século XX, historiadores europeus das trocas comerciais e da alimentação ignoraram solenemente a mandioca e sua importância nos circuitos transatlânticos. Fernand Braudel foi um deles, ao destacar a seleção e a domesticação do trigo, do arroz e do milho como base alimentar de grandes civilizações, excluindo o sorgo africano e a mandioca da América do Sul da categoria de "plantas de civilização", posto que vinham de sociedades classificadas por ele e sua cultura como "primitivas" (Panegassi, 2009, p.396). Outro a advogar explicação semelhante foi Jean Flandrin, para quem a mandioca, por não ser consumida entre as "grandes civilizações", deixou poucos registros: "a mandioca ... só serviu de base, na América, a culturas primitivas e regularmente medíocres" (Fladrin, Histoire de l'Alimentation, p.557-558, apud Rocha, 1998, p.38). Mesmo quando reconhecida, a farinha de mandioca foi destacada pela rusticidade, e seus inventores foram definidos como índios selvagens, como deixam entrever as epígrafes deste artigo.

O movimento de parte da historiografia, ao menos aquela que se debruçou sobre o Brasil, trouxe contribuições relevantes para modificar esse tipo de visão. Nesse sentido, não se pode deixar de lado a maneira como Barickman abordou o tema da lavoura de mandioca e da produção da farinha. Ao ressaltar que a mandioca é um dos alimentos básicos para cerca de 800 milhões de habitantes da zona tropical, Alfred Crosby, revisitando seu estudo clássico sobre as trocas alimentares, reconheceu que os ameríndios "desenvolveram sua própria técnica agrícola e domesticaram um bom número de nossas mais valiosas plantas comestíveis: milho, batata, batata-doce, mandioca, várias leguminosas ... tomate, cacau ... sem as quais o surgimento da civilização moderna teria sido muito difícil" (Crosby, 2013, p.23-24).

\section{SÃo Tomé E AS PRÁtiCAS ALIMENTARES INDÍGENAS}

Belas páginas foram escritas sobre a lendária passagem de são Tomé pela América do Sul. A antiguidade e persistência da narrativa fomentaram a ideia de que haveria cristãos espalhados pelo mundo graças à alegada ação apostólica do santo. Primeiros europeus a irem ao Oriente, os portugueses foram pioneiros na difusão do mito (Holanda, 1977, p.104-123).

$\mathrm{Na}$ América, os europeus depararam com crenças indígenas ancestrais, segundo as quais as marcas de pés humanos em certos terrenos seriam os passos de são Tomé. O hipotético santo teria andado distâncias imensas, a 
julgar por relatos de religiosos quinhentistas: São Vicente, Cabo Frio, Bahia, Pernambuco e Paraíba, de acordo com Simão de Vasconcelos, Frei Jaboatão e Nóbrega. Águas milagrosas e o uso de adereços com supostas relíquias do santo dos saberes úteis aproximavam a devoção no Oriente daquela percebida entre os índios da América do Sul (Holanda, 1977, p.104-123), mas o que tornaria peculiar a inventada estadia do santo entre estes últimos era a personagem Sumé, sua associação a são Tomé e o conhecimento que este teria transmitido aos índios acerca dos usos da mandioca.

Apropriado por missionários de várias ordens, o mito indígena do herói Sumé foi sincretizado com o são Tomé cristão. A associação explicava aos cristãos a existência dos saberes indígenas sobre o modo de plantar mandioca e fabricar farinha, privilegiando a ação de uma personagem de quem os conquistadores estrangeiros eram devotos. E não era só alimento: da mandioca também se fazia o cauim, como Anchieta mencionou em suas cartas (apud Moreau, 2003, p.271 e 154; Panegassi, 2009, p.399-401). O sincretismo fez eco no Paraguai, onde os jesuítas valeram-se das mesmas crenças entre os Guarani e da prática de nelas incrustar características cristãs para explicar os saberes dos índios acerca da erva-mate (Holanda, 1977, p.111): "Com tantas referências, é inegável que Tomé tenha sido visto pelos europeus como o doador da mandioca" (Cavalcante, 2008, p.32).

Nóbrega foi outro divulgador do mito: "Dele [Tomé] contam que lhes dera os alimentos que ainda hoje usam, que são raízes e ervas e com isso vivem bem" (Cavalcante, 2008, p.31). A prática não foi apenas jesuítica: capuchinhos como Yves d'Évreux narraram a crença na aparição de um maratá [enviado] de Tupã, que teria repassado aos índios conhecimentos sobre a mandioca. Como ocorria no mito do Sumé em outras partes da América do Sul, os indígenas do Maranhão mostraram-se refratários aos ensinamentos, razão pela qual o maratá partiu, não sem antes inscrever seus ensinamentos em rochedos e neles deixar marcas de seus pés. Franciscanos do início do Seiscentos também associaram os mitos indígenas a Tomé e à tradição de fazer o "mantimento da mandioca" (Sebastião do Rosário) a partir da visita do "bem aventurado apóstolo ... a esta Bahia, e lhes deu a planta da mandioca", no dizer de Vicente do Salvador (Cavalcante, 2008, p.105 e 31).

Cavalcante analisou de forma sugestiva a apropriação do saber indígena pelos colonos e missionários dos séculos XVI e XVII. Em que pesem os indícios de que outros alimentos também foram atribuídos à ação de santos, a 
mandioca ganhou destaque justamente por ser o alimento indígena utilizado com maior frequência pelos europeus:

Se, no campo simbólico, a mandioca deixou de ser uma planta nativa para se tornar uma planta sagrada, certamente não teve nenhuma melhoria em seu sabor, mas adquiriu uma força simbólica diferenciada. Isso pode ter sido muito importante naquele momento histórico ... pois a partir de então ela era uma dádiva divina quem sabe comparável ao maná do primeiro testamento, facilitando o seu consumo e livrando esse alimento de qualquer possível estigma. (Cavalcante, 2008, p.33)

Se concordarmos em que houve um grande empenho dos missionários católicos em associar a mandioca a um alimento divino pela mitológica ação de são Tomé a fim de facilitar a catequese, o mesmo empenho se verificava na evangelização dos colonos. O objetivo era fazê-los consumir farinha de mandioca, contornando resistências quanto ao gosto de um alimento associado aos hábitos indígenas. Num exercício de imaginação, poderíamos aventar que os reiterados conflitos entre colonos de São Paulo e jesuítas desde o século XVI pela administração do trabalho dos índios pudesse ter algum peso na resistência desses mesmos colonos em consumir farinha de mandioca, tão tardiamente como no século XIX, preferindo o milho, a respeito do qual os missionários talvez não tenham sido tão insistentes ao associar mito, dogma e alimentos em sua pregação religiosa.

\section{DESCRIÇÕES DA FABRICAÇÃO DA FARINHA}

Um dos primeiros a mencionar o saber indígena e as propriedades alimentícias da mandioca foi o protestante francês Jean de Léry, que fez uma descrição alongada sobre o preparo desse alimento em 1556. Ele disse haver duas espécies de raízes, aypi e maniot, que levavam de 3 a 4 meses entre a plantação e a colheita, "tornando-se tão grossas como a coxa de um homem e longas de pé e meio mais ou menos". Gabriel Soares de Sousa afirmou que havia variedades compridas e "tão grossas como a perna de um homem". Pero de Magalhães Gândavo também notou a dualidade - mandioca e aipim, esta última de maturação mais rápida e isenta de veneno ou, como disse Soares de Sousa, que atuava como contrapeçonha da mandioca e que somente os índios 
a sabiam distinguir pela cor da folhagem, "no que atinam poucos portugueses" (Bacelar, 2013, p.277).

Para Gândavo, a planta atingia a "altura de um homem”, não sendo muito grossa. Soares de Sousa descreveu a planta de modo muito semelhante: a rama teria a altura de um homem e por vezes mais. Ele também listou as variedades, relacionando-as ao tempo de maturação. A manipocamirim e a manaibuçu estavam prontas para consumo um ano depois do plantio e sobreviviam de 3 a 4 anos sob a terra, enquanto a manaitinga e a parati podiam ser colhidas 8 meses após o plantio e se estragavam depois de um ano, requerendo solos arenosos para vicejar. Todas as variedades deviam ser plantadas em tempo seco, já que as chuvas faziam apodrecer as raízes, e todas tinham na formiga seu maior inimigo natural. Por seu envolvimento com o mundo produtivo, Soares de Sousa preocupou-se com aspectos para os quais outros autores quinhentistas não atentaram ou o fizeram com ênfase menor. Um deles era o tamanho das raízes, variável conforme a "bondade da terra", do tipo de solo e das pragas.

O plantio, a colheita e o processamento eram tarefas das mulheres indígenas - "os homens não se ocupam disso", segundo Léry -, e a prática pode ter sido mantida pelos colonizadores portugueses, por exemplo, nas culturas de subsistência nos engenhos (Schwartz, 1988, p.63). O método do plantio chamou a atenção: a raiz era cortada em pedaços, enfiadas como estacas na terra, tornando "a arrebentar outras plantas de novo", conforme Gândavo. Sousa observou alguma diferença, ao afirmar que o plantio se fazia em "covas redondas como melões" nas quais se metiam três ou quatro pauzinhos da rama. Do plantio à colheita esperavam-se 9 ou 10 meses, "salvo em São Vicente que põem três anos por causa da terra ser mais fria”, nas palavras de Gândavo. Léry observou o mesmo processo ocorrendo em tempo mais curto, de 3 ou 4 meses. A durabilidade da mandioca também chamou a atenção de Gândavo: com exagero, ele acreditava que os moradores de São Vicente mantinham a raiz no solo conservada por 20 ou 30 anos.

$\mathrm{O}$ mesmo autor informa que, uma vez colhida, a mandioca recebia seu primeiro processamento: era curtida em água de 3 a 4 dias, após o que "pisam-nas muito bem" e espremem a massa em um instrumento comprido e estreito, "tecid[o] à maneira de cesto", até que "não fique dele nenhuma cousa por esgotar", extraindo-se o veneno "que se uma pessoa ou qualquer outro animal o beber, logo ... morrerá”. Soares de Sousa, diversamente, notou que o veneno era letal apenas para os humanos, pois "as raízes da mandioca comem-nas as vacas, 
éguas, ovelhas, cabras, porcos e caça do mato". Os índios retiravam a casca da mandioca usando conchas de ostras para, em seguida, ralar a raiz em uma pedra e depois espremerem a massa no instrumento chamado de tapeti ou engenho de palma. A apropriação dos saberes indígenas foi além do uso da mandioca com fins alimentares: Sousa percebeu que no chão onde caía o líquido espremido da mandioca surgiam vermes peçonhentíssimos, "com os quais muitas índias mataram seus maridos e senhores, e matam a quem querem, do que também se aproveitam ... algumas mulheres brancas contra seus maridos".

Eram as mulheres que preparavam a farinha, ralando a raiz fresca até transformá-la em "farinha alva como a neve". O passo seguinte era cozê-la: a raiz ralada era colocada pelas mulheres índias em grandes frigideiras de barro produzidas por elas, onde eram mexidas sem parar com meias cabaças "até que ... tome a forma de granizos ou confeitos”, conforme Léry. O processo levava cerca de meia hora, segundo Gândavo. Uma espécie de forno subterrâneo podia ser usado pelos índios na obtenção da farinha (Carvalho, 2000, p.32).

A farinha era feita de modos diversos. De acordo com Léry, havia uma mais cozida, dura e resistente ao tempo, utilizada pelos homens nas expedições guerreiras e chamada de uhi antan. Na descrição de Simão de Vasconcelos, referindo-se aos Tamoio do século XVI, as frotas de canoas levavam centenas de homens e mantimentos, em uma ração diária que incluía um litro de farinha (de milho ou mandioca) para cada embarcado (Holanda, 1975, p.173-174). Léry mencionou outro tipo de farinha, menos cozida, mais tenra e para consumo imediato, chamada de uhi pon e que o autor comparou ao "miolo de pão branco ainda quente". Gândavo também descreveu o método de produção da "farinha de pau" dos dois tipos mencionados por Léry: a de guerra, que duraria cerca de um ano "sem se danar", e a fresca, "mais mimosa e de melhor gosto: mas não dura mais que dois ou três dias". Foi Soares de Sousa quem explicou em detalhes os tipos e os usuários da farinha de guerra: os índios, ao fazerem jornadas fora de casa, "levam às costas ensacada em uns fardos de folhas ... esta farinha muito calcada e enfolhada", uma prática engenhosa e que impedia a água de estragar o alimento. Já os portugueses que não tinham roça ou que se encontravam nas cidades valiam-se da farinha de mandioca para sustentar todos nos engenhos.

A criação do beiju, derivado da farinha, foi creditada por Soares de Sousa às mulheres portuguesas. Na versão dele, os índios não o faziam tão fino e seco, optando pela tapioca, que ele achava mais grossa e indigesta. Essa descrição, feita em um momento de fixação mais intensa dos colonos na Bahia, apresenta 
outros elementos da interferência dos portugueses no processamento da mandioca, ditados pela preferência por um gosto mais doce, ao contrário do paladar indígena, ao qual apetecia um sabor azedo mais intenso. O relato de Sousa, movido por respostas às necessidades de colonos distantes das boticas do Reino, apresentou algumas das propriedades curativas da mandioca: ${ }^{5}$ a água de carimã ou raiz não venenosa era usada para matar lombrigas em crianças índias e portuguesas, e empregava-se a pasta da mandioca curtida como emplastro para feridas (Panegassi, 2010).

Mandioca, arroz e "outras infinidades de coisas salutíferas e de muito nutrimento" existentes no Brasil animavam Brandônio no Diálogo das grandezas do Brasil na virada dos séculos XVI e XVII (Brandão, 1956, p.16). Ele afirmou que a mandioca era o mantimento mais importante dos brancos, índios e escravos da Guiné que viviam no Brasil, sendo chamada de farinha de pau pelos portugueses, momento em que o reinol Alviano nos fez saber que, em Portugal, "quando querem vituperar o Brasil, a principal coisa que lhe opõem de mau é dizerem que nele se come farinha de pau". Insistente, Brandônio retrucava que a tal farinha de mandioca, depois do trigo, era o melhor mantimento do mundo (Brandão, 1956, p.86). Mariza Soares observou que a farinha ganhou espaço importante na obra de Brandão, "embora este fato não tenha a melhor análise por parte dos historiadores" (Soares, 2009, p.79). Se acompanharmos cronologicamente as referências à farinha de mandioca na crônica colonial, veremos nos Diálogos a confirmação do que Soares de Sousa mencionou em sua obra: entre os consumidores desse alimento estavam os “escravos da Guiné que viviam no Brasil", sobretudo a partir da intensificação da escravidão na América portuguesa em fins do século XVI, quando Brandão escrevia sua narrativa que, no mais, seguia seus antecessores ao tratar dos produtos feitos a partir da raiz, particularmente as farinhas da terra, de guerra e a puba, esta última própria para beijus.

Barléus foi outro que, no século XVII, atentou para a importância da farinha de mandioca na alimentação das conquistas holandesas. Embora tenha afirmado que essa farinha era comida dos indígenas, dos naturais ou dos roceiros menos abastados, enquanto os mais ricos comiam o trigo importado da Europa, notou também que "a soldadesca diminui já por baixa, já por morte" devido ao fornecimento insuficiente de farinha (Barleu, 1940, p.23, 73 e 46-47). O tema não era novo no século XVII nem se restringia aos holandeses: Anchieta afirmara que os ricos, sobretudo na Bahia e em Pernambuco, comiam pão de farinha de trigo e que "a massa dos colonos tinha de se contentar com 
a mandioca como alimento diário" (Carvalho, 2000, p.34). A situação persistiria nos séculos seguintes, a julgar pelo relato de Vilhena na década de 1790: "só imigrantes portugueses abastados insistiam em comer apenas pão de farinha de trigo. Para todos os demais, a farinha de mandioca geralmente tomava o seu lugar...” (Barickman, 2003, p.91).

No Brasil holandês, na falta da farinha de mandioca, havia "açúcar, em lugar de pirão", no dizer de Gonsalves de Mello, para atestar a disseminação do consumo da mandioca que, em épocas de carestia, era substituída pelo açúcar para evitar a fome. $\mathrm{O}$ consumo da farinha de mandioca era alargado nos territórios holandeses da América, como o mesmo historiador notou a respeito das renovadas ordens para se plantar mandioca nas épocas do ano em que os cativos não estavam atarefados com a cana (Mello, 1987, p.154-156).

Outro narrador da época da ocupação holandesa, se não foge ao itinerário descritivo da produção da farinha que já vimos em portugueses quinhentistas, informa sobre a introdução de metais no fazer indígena. Nieuhof afirmou que a mandioca era ralada "contra uma grande roda de quatro ou cinco pés de diâmetro, coberta por uma chapa de cobre ou de ferro repleta de furos com bordos cortantes, qual ralo para noz moscada. O movimento contínuo da roda rala a mandioca ... caindo em uma gamela. Essa roda é chamada, pelos brasileiros, ibecém babaca, e, pelos portugueses, roda de farinha..." (Nieuhof, 1942, p.284-285).

Temos aqui a única referência a uma transformação tecnológica documentada desde o início do século XVI no processo de fabricação de farinha de mandioca. No mais, tudo permaneceu como os indígenas ensinaram, sendo a chapa de metal um meio eficaz de ampliar a produtividade e diminuir a quantidade de gente envolvida na tarefa de ralar. Outras transformações ocorreram no processo produtivo entre os séculos XVI e XVII: na análise arguta de Soares, o óleo de Frans Post (1651) registrado com a legenda "Engenho" no catálogo raisonné de sua obra é um engenho de mandioca (Soares, 2009, p.66). Nessa imagem, registrou-se a transformação no processo de trabalho: em meados do século XVII e certamente antes o produto não era mais feito apenas localmente e por mulheres para a subsistência de uma comunidade indígena, mas sim produzido em escala comercial (o que não eliminou a subsistência) e por homens negros escravizados.

Mesmo quando passou a ser produzido em engenhos e de forma sistemática, a necessidade de contar com a produção indígena ainda se fazia sentir no século XVII, a julgar pelas palavras de um soldado da Companhia das Índias 
Ocidentais. Peter Hansen informa que, sobretudo nas campanhas militares e de exploração do sertão, era preciso contar com os índios, estabelecer roças próprias ou saquear os inimigos. Em algumas passagens ele documentou essas práticas: em setembro de 1647, por exemplo, ao enfrentarem portugueses no Rio Grande, estes capturaram "seis homens nossos que tinham saído para colher raízes de mandioca e tabaco verde da nossa ... roça”. Em janeiro de 1648, ouviram vozes de negros que julgaram ser fugidos e "encontramos quatro canoas grandes, carregadas pelo inimigo com raízes de mandioca”. Um desses negros "nos disse que se tratava de uns 50 homens de Henrique Dias à procura de mantimentos na roça". Meses depois, em setembro de 1648, o diário de Hansen relatou o encontro com o líder Nhanduí a fim de tranquilizá-lo sobre a proibição aos soldados a serviço da Holanda de causar danos aos brasilianos (indígenas), "mas só para que os brasilianos pudessem produzir essa farinha e transportá-la ao Rio Grande, para que servisse de sustento a eles e a nós” (Teensma; Miranda; Xavier, 2016, p.68, 69 e 71).

As informações dos cronistas se repetiam e, provavelmente, circulavam entre os colonos a partir de contatos diretos com os indígenas. Todos os testemunhos citados até aqui reforçam a manutenção de um costume indígena apropriado pelos colonos em terra e imposto à dieta dos escravos. Tardiamente, no século XIX, outros autores descreveram a produção da mandioca. Lindley viu o processo na Bahia em 1802, dizendo que o plantio se fazia cortando o caule em pedaços e enterrando-os, e que o arbusto atingia seis pés de altura. A colheita ocorria um ano depois, e o tamanho das raízes dependia da fertilidade da terra: "Arrancadas as raízes e retirada sua casca, resta uma substância farinácea, leitosa e glutinosa, que é reduzida a pequenos pedaços, num ralador giratório, recoberto com uma chapa de cobre perfurado, caindo tudo num cocho ... É então posta a secar em panelas rasas, a fogo brando, até que se evapore toda a umidade, assemelhando-se, então, a uma substância granulada e seca, pronta para ser usada". O contrabandista inglês sabia que a farinha era utilizada pelos índios e achava que os portugueses a tinham adotado "pois o trigo não se adapta a este solo e a mandioca é cultivada com um centésimo do trabalho e das despensas daquele" (Lindley, 1969, p.52).

Daí por diante, muitos viajantes observaram a farinha de mandioca impregnada às práticas alimentares dos brasileiros, como Adalberto da Prússia, de passagem pelo Rio de Janeiro, onde lhe serviram um bom jantar sem pão: "em lugar dele come-se farinha de mandioca com tudo. Experimentei-a hoje pela primeira vez mas quase que não pude engoli-la...” (Prússia, 2002, p.75). 
O príncipe alemão, que chegou ao Rio em 1842, prosseguiu a viagem pela Amazônia, onde reencontrou a farinha junto aos Juruna, que continuavam a fazê-la do modo descrito pelos primeiros colonizadores:

Primeiro faz-se a 'farinha de água' ... Em seguida descascam-se ... e põem-se numa caixa com um escoadouro. Secam aí dentro ... esfarelam-se em seguida entre os dedos e torram-se em grandes cuias (tigelas), até ficarem reduzidas a um pó grosso. A chamada ... 'farinha-seca' ... cujo modo de preparar é o seguinte: raspam-se e limpam-se as raízes frescas e trituram-se num ralador; em lugar deste os índios servem-se também de um toro coberto de espinhos; em seguida põe-se esta massa suculenta num canudo entretecido de folhas de palmeiras, com 1,80 a 2 metros de altura e alguns centímetros de diâmetro, chamado 'tipiti'. Deste canudo, posto em pé, escorre, comprimido pelo próprio peso, o suco venenoso, isto é, o suco contendo ácido prússico da farinha do tucupi. Quando fica bastante seca, tira-se e torra-se como se faz com a farinha de água... (Prússia, 2002, p.332-333) ${ }^{6}$

As ligeiras diferenças entre as descrições podem nos informar muito mais sobre as diferenças no olhar e as intenções dos narradores do que propriamente sobre a diversidade no processo de fabrico da farinha. Cabe mencionar uma função das plantações de mandioca que não chamou a atenção da maioria dos cronistas: o fato de que ela também era cultivada para "amaciar" o solo antes de se plantar cana-de-açúcar pela primeira vez, ou sua introdução se fazia em terras cansadas pelo cultivo de cana, como cultura de descanso (Barickman, 2003, p.106-107; Schwartz, 1988, p.103; Crosby, 2013, p.24).

\section{O CONSUMO INTERNO DA FARINHA DE MANDIOCA}

Desde a constatação da existência de uma técnica indígena de processar a mandioca, a farinha dessa raiz manteve-se no consumo alimentar de todos os envolvidos na colonização e desde então manteve-se à mesa. Em 1889, o francês Max Leclerc desembarcou no Rio de Janeiro para escrever sobre a recém-instaurada República e observou aspectos da vida cotidiana nos meses que passou no país, como o consumo de mandioca, arroz, feijão preto e milho (Leclerc, 1942, p.175-176). Sem pretender, a observação dava conta da longevidade do consumo interno da farinha de mandioca.

A conexão entre consumo interno e sustento do comércio e dos navegadores era antiga, como podemos ver no alvará de fevereiro de 1688, que 
obrigava os plantadores de cana da Bahia a plantar mandioca, bem como nas posturas da Câmara de Salvador que tentaram obrigar os donos de embarcações negreiras a plantarem mandioca (Prado Jr., 1986, p.163-164). Nem sempre a determinação era cumprida, como em 1703, quando o governador do Rio de Janeiro referiu-se a uma lei anterior sobre o assunto que os camaristas da cidade julgavam "se não podia executar em tudo sem grande prejuízo deste povo" (AHU, Rio de Janeiro, Caixa 7, doc. 790). Quase ao mesmo tempo, enviou-se uma série de cartas de Pernambuco pedindo alterações na lei para conceder aos lavradores de mandioca com mais de seis escravos o mesmo privilégio dados aos plantadores de cana e aos "lavradores de pão do Reino" - qual seja, o de não terem suas dívidas executadas com a perda de suas propriedades -, a fim de sanar a falta de farinha "para o sustento destes povos e a expedição das frotas”. A demanda pareceu justa ao Conselho Ultramarino, na medida em que a farinha era "o pão e sustento daquela conquista". O privilégio lhes foi concedido em setembro de 1703 (AHU, Pernambuco, Caixa 21, docs. 1957 e 1967 e AHU, Pernambuco, Caixa 22, doc. 2004).

As determinações legais não eram capazes de solucionar a falta endêmica do gênero, a julgar pelas queixas contidas na correspondência colonial. No Maranhão do século XVIII, a avaliação das roças de mandioca para fazer derramas que garantissem o abastecimento das tropas militares provocava descontentamento e fome em outros segmentos da população (AHU, Maranhão, Caixa 16, doc. 1590). Da Bahia, mais queixas vinham dos lavradores de mandioca do Recôncavo e do sertão, demonstrando a dificuldade no convívio entre atividades econômicas. Em Jaguaripe, reclamavam do dano causado pelo gado em suas roças, confirmando a afirmação de Soares de Sousa sobre o consumo de raízes da planta pelos animais. Os lavradores pediam que os donos do gado "fizessem cercas fortes e tais que as não possam romper o dito gado", no que foram atendidos pelo rei, ainda que na prática isso não deva ter solucionado o problema. O conflito entre lavradores e criadores persistiu, pois era difícil fazer os poderosos da vila cumprirem a provisão real que determinava o erguimento de cercas (AHU, Bahia, Caixa 64, doc. 5444; Caixa 74, doc. 6182; Caixa 179, doc. 13377; Caixa 180, doc. 13400). O confronto não se limitou ao Recôncavo e ocorreu em outros lugares por onde a pecuária avançava, como em Jacobina (AHU, Bahia, Caixa 152, doc. 11613).

A questão do preço da farinha era lamento constante em Pernambuco e no Ceará, em razão da preferência dos senhores locais por negócios mais lucrativos como o plantio da cana-de-açúcar e a criação de gado (AHU, 
Pernambuco, Caixa 136, doc. 10183; AHU, Ceará, Caixa 9, doc. 590; Caixa 207, doc. 14108; Caixa 226, doc. 15295; Caixa 230, doc. 15543 e Caixa 234, doc. 15811). Em mais de uma ocasião, as câmaras pernambucanas reportaram a necessidade da intervenção real para fazer cair os preços, em função da preferência dos tropeiros em levar o algodão (AHU, Pernambuco, Caixa 193, doc. 13277; AHU, Pernambuco, Caixa 198, docs. 13603 e doc. 13591) e pela ampliação do consumo de farinha de pau no sustento dos moradores e das tropas aquarteladas naquela capitania. Todos sofriam com a "seca que tem abrasado este clima” entre fins do século XVIII e início do XIX (AHU, Pernambuco, Caixa 242, doc. 16206), ao ponto de Pernambuco e a Paraíba terem de recorrer à farinha de outras capitanias (AHU, Bahia, caixa 19, doc. 1704). Ao recorrerem às partes do Sul para receberem o tão necessário sustento, os pernambucanos lidaram com a recusa da Câmara do Rio de Janeiro, empenhada em proibir a remessa prometida pelo vice-rei Conde de Resende ao governador de Pernambuco. Em ofício do governador de Angola para Resende em novembro de 1791, alegavam-se a guerra e a esterilidade como inviabilizadores do "suficiente sustento de primeira necessidade aos seus habitantes [de Angola]", pedindo socorro "particularmente de farinhas" (AN, Fundo Ministério do Reino e Império, Caixa 502 - Corresp. do governador de Angola com os vice-reis do Brasil, 1769-1807).

A situação no Rio de Janeiro levou a uma investigação por contrabando “em detrimento dos povos" em 1792 (AHU, Rio de Janeiro, Caixa 145, doc. 11246; AHU, Rio de Janeiro, Caixa 147, docs. 11332 e 11353) e a tumultos populares pela falta de farinha de mandioca no início de 1793: “Já dei conta da ... carestia de mantimentos que tem havido nesta cidade [Rio de Janeiro] e que fizeram o objeto da devassa a que procedi ... A repartição [de farinha] feita pelos militares tem promovido clamor e tumulto populares no Largo do Palácio, na provedoria e na praia, e murmurações, pois que a pobreza só tem sido servida de pancadas..." (AHU, Rio de Janeiro, Caixa 147, docs. 11355 e 11559). O crescimento da lavoura de exportação levou a sucessivas crises de subsistência e inquietação social, "sobremodo em Salvador, pois cada dia recebia mais escravos, e se agravava a questão dos preços altos dos alimentos" (Bacelar, 2013, p.277). Isso se deu para além do tempo em que Vilhena escreveu suas notícias, pois a farinha manteve sua posição primordial na dieta dos baianos ao longo da primeira metade do século XIX. A escassez levava ao aumento nos preços: "nesses momentos, os pobres não se amotinavam nas ruas ... pedindo pão; o que pediam era farinha ... que continuava a ser a base de sua 
subsistência...” (Barickman, 2003, p.95 e 140). De acordo com Caio Prado Jr., Bahia e Pernambuco viveram na época colonial em um "estado crônico de carestia e crise alimentar que frequentemente se tornam em fome declarada e generalizada", sobretudo quando as culturas alimentares eram abandonadas para ceder espaço e mão de obra à lavoura de exportação (Prado Jr., 1986, p.163-165). Embora não fosse determinante para a ocorrência de fome crônica, o estio assolou por anos o norte da colônia e a cultura da mandioca: "as grandes secas de três anos sucessivos que tiveram princípio em noventa e um e findaram em noventa e três ... arruinaram esta capitania e a sua população, da qual morreu a terça parte..." (AHU, Pernambuco, Caixa 190, doc. 13117). No Pará não se experimentava seca: a dificuldade era com a mão de obra necessária ao cultivo de mandioca, mas também de cana e outras plantações (AHU, Pará, Caixa 87, docs. 7074 e 7082), sobretudo pela incapacidade da Companhia do Grão-Pará e Maranhão em trazer os “operários” necessários.

A correspondência colonial setecentista e do início do Oitocentos é pródiga em exemplos da importância da mandioca e da farinha para o consumo local e da circulação do produto entre diferentes capitanias, sobretudo nos momentos de desabastecimento (AHU, Pará, Caixa 47, doc. 4298). As lutas no Prata mobilizavam tropas militares e agricultores capazes de fornecer farinha de mandioca para a manutenção da guerra e dos índios trazidos pelo Conde de Bobadela desde as missões castelhanas para Viamão em 1764: "Não posso entender qual foi a utilidade que se achou em trazer os ditos índios aos domínios portugueses", escreveu o vice-rei, pois a vinda deles só teria aumentado o consumo de carne, farinha e vestuário (AHU, Rio de Janeiro, Caixa 72, doc. 6614). O contínuo aumento dos habitantes não deve ter causado grande carestia na capitania no decorrer do tempo, se julgarmos pelo apelo de um negociante para vender farinha de mandioca à vizinha Santa Catarina (AHU, Brasil-Avulsos, Caixa 23, doc. 2008). Na região amazônica, o plantio de mandioca também era regular e, se compunha a base da alimentação dos moradores, nem sempre estava disponível para atender a todas as demandas, como a dos espanhóis que trabalhavam na demarcação da fronteira entre os domínios das Coroas ibéricas na capitania do Rio Negro e pediam centenas de alqueires de mandioca para alimentar sua comitiva a partir de 1783 (AHU, Rio Negro, Caixa 7, doc. 12; Caixa 8, docs. 2 e 6; Caixa 14, doc. 21).

O circuito do consumo local da farinha incluía outro tipo de gente: a população flutuante, formada basicamente por soldados e marinheiros. Nas 
cidades portuárias, sobretudo, essa população era significativa, como notou Barickman para o caso de Salvador:

centenas de barcos ... chegavam de vários pontos do Recôncavo e os navios maiores do comércio costeiro e transatlântico podiam, a qualquer dia, pôr em terra até 2.200 marinheiros. Os navios que chegavam à cidade vindos da África traziam não só marinheiros, mas também escravos. Porto dos mais importantes do tráfico negreiro, Salvador abrigava os cativos africanos recém-chegados até que fossem vendidos para engenhos e fazendas do interior ou reexportados para outras partes do Brasil ... Durante sua permanência na cidade, tanto marinheiros quanto escravos em trânsito tinham de comer; eles também, portanto, faziam sentir sua presença no mercado urbano de Salvador. (Barickman, 2003, p.99)

\section{O CONSUMO TRANSATLÂNTICO DA FARINHA DE MANDIOCA}

A produção e o consumo da farinha de mandioca não envolviam apenas índios, negros e brancos na América portuguesa. Resistente à ação do tempo, a farinha de mandioca americana foi essencial também nas longas viagens marítimas entre os domínios portugueses, sendo encontrada inclusive nos navios da Carreira da Índia, como a Santa Maria da Barca em 1559.7 Muito provavelmente essa farinha fora embarcada 2 anos antes no Brasil, onde o navio fizera escala não planejada a caminho da Ásia. A existência da farinha de mandioca nessa embarcação não era ocasional nem se restringiu ao século XVI: como constatou Holanda, um relatório consular francês de 1786 notava as perdas de homens nos navios portugueses da derrota da Índia que ainda se verificavam naquela altura do século XVIII e só puderam ser evitadas graças a uma dieta que consistia, "além do uso moderado de alimentos salpresos, no abundante consumo de arroz e mandioca, especialmente mandioca” (Holanda, 1977, p.269-270). Há notícias, também, da transplantação de mandioca e outros vegetais da América portuguesa para Goa no século XVI, considerando as semelhanças climáticas entre os dois territórios (Bracht; Conceição; Santos, 2011, p.12).

Desde cedo os conquistadores atentaram para o saber indígena americano no preparo desse alimento substancioso e o fizeram circular por diferentes continentes pelas rotas marítimas. Gabriel Soares de Souza oferece pistas dessa circulação ao afirmar que a farinha de guerra era a única opção de sustento nas viagens de retorno a Portugal, na medida de um alqueire da Bahia para cada 
homem por mês: "os navios que vêm do Brasil para estes reinos não têm outro remédio de matalotagem, para se sustentar a gente até Portugal, senão o da farinha de guerra ... Também costumam levar para o mar matalotagem de beijus grossos muito torrados, que dura um ano e mais sem se danarem, como a farinha de guerra..." (Sousa, 1987, p.178). Se em fins do século XVI a prática já era corrente, ela foi mantida e institucionalizada nos séculos seguintes a partir das capitanias costeiras da América. Brandão, referindo-se ao Rio de Janeiro, disse que ali "carregam de farinha da terra, de que abunda toda esta capitania em grande quantidade e dali a levam para Angola, onde se vende por subido preço" (Brandão, 1956, p.59-60; Soares, 2009, p.79; Bezerra, 2010, p.142-152).

Além do consumo local, as fontes indicam sinais de dois circuitos integrados de circulação atlântica da farinha de mandioca dos índios americanos: um destinado às costas africanas, outro a Portugal.

A presença da farinha era essencial no tráfico de escravos e na subsistência das populações africanas ao sul do Saara. David Eltis fez uma afirmação curiosa, segundo a qual plantas como a mandioca e o milho ainda não haviam se dispersado pela África antes do declínio do tráfico de escravos na década de 1790 e sua supressão nos anos 1860 (Eltis, 1987, p.64), o que não encontrou eco nos estudos de outros historiadores. Crosby, por exemplo, cita historiadores da alimentação segundo os quais os portugueses haviam introduzido o cultivo da mandioca no Congo desde pelo menos 1558 (Crosby, 2013, p.24). Marinheiros em circulação e africanos submetidos ou não à autoridade lusa sentiam os efeitos das reduzidas calorias de suas dietas.

Nos tumbeiros capturados pelas autoridades brasileiras e inglesas na primeira metade do século XIX, a farinha como alimento básico de escravos e marinheiros era uma constante (Rodrigues, 2005). Traficantes importantes como Elias Antônio Lopes empregavam algum dinheiro na compra de farinha de mandioca para mantimento de escravos embarcados. Pelo inventário dos bens da galera Paquete Infante, de sua propriedade, podemos ter uma ideia do montante representado pela farinha na armação de um negreiro. O bem de maior preço no navio era o casco, equivalente a quase $50 \%$ do valor, enquanto o carregamento de 295 sacos de farinha equivalia a 3\% do valor total da armação (AN, Códice 789, fl. 33). Para um traficante, o valor da farinha de mandioca era ínfimo, sobretudo quando se pensava no retorno garantido por ela como caloria básica de um carregamento de mercadoria humana. 
As leis que se referiam às plantações de mandioca também regularam o abastecimento do tráfico, embora não fossem cumpridas com rigor. A lei de arqueação, alterada em 1758, previa a reserva de espaço nos navios negreiros não só destinados aos escravos, mas também para o armazenamento de mantimentos necessários à viagem (Biblioteca Nacional, Divisão de Manuscritos, a partir daqui BNDM, II - 33, 29, $\left.31 \mathrm{n}^{\circ} 1\right)$.

A inserção da farinha de mandioca na dieta marítima criava uma concorrência nem sempre salutar. Conjugada a períodos de ampliação do comércio de escravos e às conjunturas africanas de seca e fome e de crescimento demográfico e econômico na América portuguesa, a farinha de mandioca era bastante disputada, gerando "o lucro de uns e a fome de outros" (AHU, Bahia, Caixa 8, doc. 1351). No tráfico de africanos, a farinha de mandioca preservaria muitas vidas. Não por acaso, as capitanias manteriam roças de mandioca em seus territórios, mas também na África diferentes regiões tornaram-se produtoras da raiz, para subsistência e o abastecimento dos navios em viagem aos portos da América portuguesa. Ao fazer um inventário dos domínios africanos de Portugal, Cunha Matos informou sobre a presença da farinha em Cabo Verde e São Tomé, onde nunca era suficiente devido às secas (Matos, 1963, p.55 e 134; BNDM, 22,2,49). ${ }^{8}$

A presença do alimento ficou mais bem documentada em Angola, decerto em razão do volume do tráfico realizado ali e da presença mais incisiva dos portugueses no litoral e nas feiras do interior. Uma carta régia de 1762 mandou criar em Luanda um terreiro para vender farinha da terra, mas a Câmara local suspendeu a ordem alegando falta de recursos para manter o terreiro e falhas na fabricação feita localmente: "a farinha posta em montes nas tulhas ... se destrói brevissimamente, não só pela umidade do país mas porque os fabricantes que são negros a não secam". A Câmara pretendia contornar as questões econômica e ambiental: fixar um preço máximo para a farinha e estocá-la em lugares diferentes para evitar o ataque do salalé, a temida formiga branca que arruinava tudo em uma só noite (AHU, Angola, Caixa 45, doc. 23). ${ }^{9}$

Consumida nas embarcações negreiras, a farinha de mandioca tinha ainda mercado no continente africano entre populações não necessariamente envolvidas no tráfico. Era difícil consegui-la mesmo com a transmigração da planta para partes da África. Autores como Alberto da Costa e Silva e Luiz Felipe de Alencastro são convincentes quanto a isso. Para Silva, não foi apenas a planta em mudas e a farinha que atravessaram o Atlântico da América para a África, mas também o modo de confeccionar a farinha, feita até hoje pelos métodos 
criados pelos índios da América do Sul (Silva, 2006, p.30 e 36). Alencastro, por sua vez, atribuiu o sucesso dessa transferência alimentar à ausência de pragas naturais da mandioca na África, cuja agricultura se expandiu do sul do Saara ao sul de Moçambique e Angola, tornando-se "a mais importante fonte primária de caloria da dieta dos africanos" assim como "o alimento básico de escravos, soldados, mareantes, barqueiros fluviais e todos os outros intervenientes no sistema do Atlântico Sul" desde fins do século XVI. ${ }^{10}$

A correspondência dos governadores de Angola pedindo que os navios viessem do Brasil carregados de farinha de mandioca e outros víveres para a viagem de volta reforçam a relevância do produto nas conexões imperiais lusas. Também o confirmam as repetidas menções à presença dessa farinha nos estoques alimentares dos navios negreiros apreendidos no Atlântico pelos cruzeiros repressivos dos ingleses até meados do século XIX. É quase impossível documentar a existência de roças de subsistência ao longo dos trajetos percorridos pelas caravanas de escravos entre o interior e a costa africana, mas é certo que desde muito cedo os portugueses tinham introduzido mudas de alimentos americanos em Angola, sendo a mandioca o principal deles. Podemos afirmar que esses vegetais criaram práticas alimentares novas, além de serem resistentes às secas e pragas locais. "Com isso, esses produtos agrícolas contribuíram para uma diminuição nas taxas de mortalidade, estimulando o aumento do número de cativos em potencial para o tráfico, além de ter mantido vivos os africanos em trânsito entre o local da captura e a costa" (Rodrigues, 2005, p.72).

A circulação da farinha desde o século XVI não se restringia ao circuito sul-sul nem ao consumo local. Parte da produção também se destinava ao Reino de Portugal. Nos séculos da colonização lusa, as frotas que seguiam para lá se ressentiam quando escasseava a "farinha de guerra", certamente a mesma que os indígenas usavam havia muito tempo. ${ }^{11} \mathrm{~A}$ farinha de guerra era mantimento essencial nos navios da Armada ou mercantes em viagens transatlânticas entre os portos da América portuguesa e o Reino. A documentação sobre isso também é farta e inequívoca, e dela selecionei alguns exemplos.

Inicialmente, cabe notar que o sabor da mandioca enfrentava a resistência de reinóis que com ela tinham contato mais ocasional que os moradores da América. Na década de 1730, talvez para atender a uma reivindicação de marinheiros e soldados envolvidos nas guerras do Prata, Gomes Freire de Andrade mandou instalar um moinho de milho na Ilha das Cobras e dessa farinha mandar fazer biscoitos misturados com farinha de trigo, "porque a 
gente do mar aceitaria melhor este mantimento" do que o biscoito de farinha de mandioca (AHU, Rio de Janeiro, Caixa 29, doc. 3099). O alimento também era sinal de distinção social que, na visão de autoridades, não deveria mudar. Refiro-me a Pina Manique, intendente da polícia lisboeta no final do século XVIII, que tratou da questão da farinha de trigo introduzida pelos espanhóis pela Colônia do Sacramento a preços baixos. Tal comércio deveria ser evitado, pois "a barateza é atrativo para a pobreza, que em concurso com a farinha de mandioca, hão de preferir a primeira a esta” (AHU, Rio de Janeiro, Caixa 129, docs. 10247 e 10275).

Muitas embarcações mercantes que partiam em direção a Portugal levavam a preciosa farinha de mandioca, em meio a outras cargas com mercado certo. ${ }^{12}$ Em 1773, os 14 navios que zarparam do Maranhão para o Reino não puderam carregá-la: com a estação chuvosa, "apodreceu a maior parte da mandioca ... havendo de se suprir esta falta com arroz” (AHU, Maranhão, Caixa 47, doc. 4588). Em Pernambuco experimentava-se a carestia em fins da década de 1780 pois, se o estímulo às lavouras fizera os preços caírem, a chegada das frotas vindas do Reino para carregar açúcar concorria com o consumo local. O governador tentou contornar o problema exigindo dos capitães dos navios "uma conta exata da farinha que tinham comprado e do número da gente das suas equipagens, e a fazê-los assinar um termo ... em que se obrigavam a não levarem mais do que a necessária para a viagem", sendo as sobras entregues nos armazéns da Marinha, em Lisboa. ${ }^{13} \mathrm{O}$ Reino, todavia, demandava mais farinha de pau do que a sobra das viagens, e, ao que tudo indica, o consumo caiu em desuso no decorrer do século XIX como parte da ração dos marinheiros lusos. Em fins do Oitocentos, estudo sobre a higiene dos marinheiros deixava claro que "a farinha ordinariamente usada pela alimentação de bordo é a de trigo..." (Silveira, 1897, p.89). Mas enquanto o comércio colonial manteve-se ativo entre Portugal e a América, era preciso enviar farinha para o Reino. O Conde de Resende enumerou os motivos do atraso nas remessas: os fretes mais vantajosos de outros produtos, a concorrência da cana com o cultivo da mandioca e a procura pelas tripulações de "embarcações grandes e pequenas, que navegam para a Europa, Costa da África e do Brasil" (AHU, Rio de Janeiro, Caixa 164, doc. 12254). Essa visão, que representa o modo como as autoridades consideravam o problema, podia não ser compartilhada pelos lavradores coloniais, como fizeram os produtores do Recôncavo Baiano, que no início do século XIX ainda representavam o "maior celeiro produtor de gêneros de primeira necessidade", embora áreas novas de plantio de mandioca tenham 
surgido no sul da Bahia (Castellucci Jr., 2008, p.262), ao pedirem autorização para comercializar a farinha de mandioca diretamente a bordo dos navios mercantes, tentando contornar as taxas cobradas pelo Celeiro Público, onde eram obrigados a vender seu produto. ${ }^{14} \mathrm{Uma}$ alternativa malsucedida ou sequer tentada a sério foi a aclimatação da planta da mandioca em Portugal (AHU, Rio de Janeiro, Caixa 164, doc. 12254; Caixa 165, doc. 12276; AHU, Pernambuco, Caixa 207, doc. 14110).

\section{CONSIDERAÇÕES FINAIS}

No início da colonização, o conhecimento indígena transmitido oralmente através das gerações foi considerado herança mitológica de uma entidade católica, ajudando a justificar o domínio e a desqualificar os saberes e seus detentores. Ocorrências em pleno século XXI deixam claro que somos herdeiros e praticantes de uma visão preconceituosa sobre as culturas indígenas, na medida em que os conhecimentos deles, construídos ao longo do tempo, são julgados como algo que qualquer pessoa poderia saber e fazer.

Os índios da América do Sul foram capazes de transformar uma raiz potencialmente venenosa em alimento básico da sua dieta e da alimentação dos colonizadores, dos navegadores e dos africanos escravizados. O consumo do produto não se deu apenas na América, mas em todos os continentes onde a dominação europeia se fez sentir.

$\mathrm{Na}$ história atlântica da farinha de mandioca, podemos cruzar temáticas por vezes estanques nas interpretações históricas: formação do mundo colonial, história indígena, religiosidade, estudos agrários, comércio em escalas local e mundial, cultura de subsistência conjugada à questão da roça escrava, história da alimentação, tráfico de escravos e história marítima, para mencionar apenas alguns recortes possíveis. Tudo isso percorrendo cinco séculos, quatro continentes e registros históricos fartos: como bem disse Barickman (2003, p.89), "sobre nenhum outro gênero alimentício, exceto talvez a carne verde, há tanta documentação". Sob qualquer perspectiva temática, temporal ou espacial, há muito ainda por ser feito na escrita de uma história que leve em conta os limites regionais e nacionais ou que considere o mundo sem fronteiras como uma invenção de nossos antepassados, processo no qual há mais intervenientes do que temos sido capazes de admitir. 


\section{REFERÊNCIAS}

ALENCASTRO, Luiz Felipe de. A rede econômica do mundo atlântico português. In: BETHENCOURT, Francisco; CURTO, Diogo Ramada (Dir.) A expansão marítima portuguesa, 1400-1800. Lisboa: Ed. 70, 2010.

BACELAR, Jeferson. A comida dos baianos no sabor amargo de Vilhena. Afro-Ásia, Salvador, n.8, 2013.

BARICKMAN, Bert J. Um contraponto baiano: açúcar, fumo, mandioca e escravidão no Recôncavo, 1780-1860. Rio de Janeiro: Civilização Brasileira, 2003.

BARLEU, Gaspar. História dos feitos recentemente praticados durante oito anos no Brasil e noutras partes sob o governo do ilustríssimo João Maurício, conde de Nassau etc., ora Governador de Wesel, Tenente-General de Cavalaria das Províncias-Unidas sob o Príncipe de Orange. Rio de Janeiro: Serv. Gráf. Min. da Educação, 1940.

BEZERRA, Nielson Rosa. Mosaicos da escravidão: identidades africanas e conexões atlânticas do Recôncavo da Guanabara (1780-1840). Tese (Doutorado em História) - Universidade Federal Fluminense (UFF). Niterói, 2010.

BRACHT, Fabiano; CONCEIÇÃO, Gisele Cristina da; SANTOS, Christan Fausto Moraes dos. A América conquista o mundo: uma história da disseminação das especiarias americanas a partir das viagens marítima do século XVI. Revista Brasileira de Pesquisa em Alimentos, v.2, n.1, jan./jun. 2011.

BRANDÃO, Ambrósio Fernandes [atribuído a]. Diálogos das grandezas do Brasil. Salvador: Progresso, 1956.

CARVALHO, Filipe Nunes de. Cambiantes do paladar: a alimentação dos colonos no Brasil do século XVI. Penélope, v.23, p.31-39, 2000.

CASTELLUCCI JR., Wellington. Entre veredas e arrabaldes: histórias de escravos e forros na comarca de Nazaré, Bahia, 1830-1850. História \& Perspectivas, v.39, p.261-304, jul./dez. 2008.

CAVALCANTE, Thiago Leandro Vieira. Apropriações e ressignificações do mito de São Tomé na América: a inclusão do índio na cosmologia cristã. Dissertação (Mestrado em História) - Universidade Federal da Grande Dourados (UFGD). Dourados, 2008.

CROSBY, Alfred W. Gran historia como historia ambiental. Relaciones, v.34, n.136, p.21-39, otoño 2013.

CROSBY JR., Alfred W. The Columbian Exchange: Biological and Cultural Consequences of 1492. Westport, Conn.: Greenwood, 1972.

EDWARDS, William Henry. A voyage up the River Amazon including a residence at Pará. New York: D. Appeton \& Company, 1847.

ELTIS, David. Economic Growth and the Ending of the Transatlantic Slave Trade. New York \& Oxford: Oxford University Press, 1987. 
FLECK, Eliane Cristina Deckmann. Em memória de São Tomé: pegadas e promessas a serviço da conversão do gentio (séculos XVI e XVII). Estudos Ibero-Americanos, v.36, n.1, jan./jun. 2010.

GÂNDAVO, Pero de Magalhães. História da Província de Santa Cruz. Belo Horizonte: Itatiaia; São Paulo: Edusp, 1980.

HOLANDA, Sérgio Buarque de. Caminhos e fronteiras. 2.ed. Rio de Janeiro: J. Olympio Ed., 1975.

. Visão do paraíso: os motivos edênicos no descobrimento e colonização do Brasil. 3.ed. São Paulo: Cia. Ed. Nacional; Secret. Est. Cultura, 1977.

LECLERC, Max. Cartas do Brasil. São Paulo: Cia. Ed. Nacional, 1942.

LÉRY, Jean de. Viagem à terra do Brasil. Rio de Janeiro: Biblioteca do Exército Ed., 1961.

LINDLEY, Thomas. Narrativa de uma viagem ao Brasil. São Paulo: Cia. Ed. Nacional, 1969.

MATOS, Raimundo José da Cunha. Compêndio histórico das possessões portuguesas na África. Rio de Janeiro: Arquivo Nacional, 1963.

MELLO, José Antônio Gonsalves. Tempo dos flamengos. 3.ed. Recife: Fundaj; Ed. Massangana; Brasília: INL, 1987.

MOREAU, Filipe Eduardo. Os índios nas cartas de Nóbrega e Anchieta. São Paulo: Annablume, 2003.

NIEUHOF, Joan. Memorável viagem marítima e terrestre ao Brasil. São Paulo: Martins, 1942.

PANEGASSI, Rubens L. O cauim e o pão da terra: a criação de um horizonte comestível na América portuguesa. In: ALGRANTI, Leila Mezan; MEGIANI, Ana Paula (Org.) O Império por escrito: formas de transmissão da cultura letrada no mundo ibérico (sécs. XVI-XIX). São Paulo: Alameda, 2009.

. O saber medicinal, a salubridade e a produção de significados nas crônicas do século XVI. Histórica, Revista Eletrônica do Arquivo Público do Estado de São Paulo, v.44, out. 2010.

PRADO JR., Caio. Formação do Brasil contemporâneo: colônia. 19.ed. São Paulo: Brasiliense, 1986.

PRÚSSIA, Adalberto da. Brasil: Amazonas-Xingu. Brasília: Senado Federal, 2002.

RELAÇÃO do naufrágio da nau Santa Maria da Barca, de que era capitão D. Luiz Fernandes de Vasconcelos, a qual se perdeu vindo da Índia para Portugal no ano de 1559. In: PERES, Damião (Ed.) História Trágico-Marítima. v.3. Porto: Portucalense, 1942.

ROCHA, Rui. A viagem dos sabores: ensaio sobre a história alimentar (séculos IX-XIX) seguido de cem receitas que em várias mundos se encontram. Lisboa: Inapa, 1998. 
RODRIGUES, Jaime. De costa a costa: escravos, marinheiros e intermediários do tráfico negreiro de Angola ao Rio de Janeiro (1780-1860). São Paulo: Companhia das Letras, 2005.

. No mar e em terra: história e cultura de trabalhadores escravos e livres. São Paulo: Alameda, 2016.

. Um sepulcro grande, amplo e fundo: saúde alimentar no Atlântico, séculos XVI ao XVIII. Revista de História, São Paulo, n.168, p.325-350, jan./jun. 2013.

RODRIGUES, José Honório. História da história do Brasil, $1^{a}$ parte: a historiografia colonial. 2.ed. São Paulo: Cia. Ed. Nacional, 1979.

SALVADOR, Frei Vicente do. História do Brasil, 1500-1627. 7.ed. Belo Horizonte: Itatiaia; São Paulo: Edusp, 1982.

SCHWARCZ, Lilia Moritz. O sol do Brasil: Nicolas-Antoine Taunay e as desventuras dos artistas franceses na corte de d. João. São Paulo: Companhia das Letras, 2008.

SCHWARTZ, Stuart B. Segredos internos: engenhos e escravos na sociedade colonial (1550-1835). São Paulo: Companhia das Letras, 1988.

SILVA, Alberto da Costa e. A enxada e a lança: a África antes dos portugueses, 3.ed. Rio de Janeiro: Nova Fronteira, 2006.

SILVEIRA, João Severo Duarte da. Breve estudo sobre a hygiene do marinheiro. Porto: Typ. do Commercio do Porto, 1897.

SOARES, Mariza de Carvalho. Engenho sim, de açúcar não: o engenho de farinha de Frans Post. Varia Historia, Belo Horizonte, v.25, n.41, p.61-83, jan./jun. 2009.

SOUSA, Gabriel Soares de. Tratado descritivo do Brasil em 1587. 5.ed. São Paulo: Cia. Ed. Nacional; Brasília: INL, 1987.

TEENSMA, Benjamin N.; MIRANDA, Bruno R. F.; XAVIER, Lucia F. W. (Org.) Viagem ao Brasil (1644-1654). Recife: Cepe, 2016.

\section{Fontes manuscritas:}

>> Arquivo Nacional (Rio de Janeiro)

Códice 789 - Inventário dos bens da casa do finado Conselheiro Elias Antonio Lopes.

Fundo Ministério do Reino e Império, Caixa 502 - Correspondência do governador de Angola com os vice-reis do Brasil, 1769-1807.

>> Biblioteca Nacional (Rio de Janeiro)

22,2,50 - Ofícios de Miguel Antonio de Mello, governador de Angola (1789-1801): ofício de Miguel Antônio de Melo a Rodrigo de Souza Coutinho, 20 de fevereiro de 1800. 22,2,49 - Cartas do Brasil ao governador de Angola D. Miguel Antonio de Mello (17971800): carta de João Batista e Silva, governador de São Tomé e Príncipe, ao governador de Angola, 31 de out de 1799.

II - 33,29,31 número 1: Ofício de D. Marcos de Noronha a Tomé Joaquim da Costa Corte Real, datado da Bahia, setembro de 1758. 
>> Arquivo Histórico da Marinha (Lisboa):

Caixa 363, Pasta 67: Intendências da Marinha no Brasil - Pernambuco, 1798-1822. >> Arquivo Histórico Ultramarino (Lisboa), Conselho Ultramarino: Angola, Caixas 45, 48, 5 e 62; Angola, Códice 1630; Bahia, Caixas 19, 64, 74, 179, 180, 191 e 248; Brasil - Avulsos, Caixa 23; Ceará, Caixas 9, 15, 207, 226 e 234; Maranhão, Caixas 16, 47, 102, 111, 113 e 115; Pará, Caixas 47 e 87; Pernambuco, Caixas 21, 22; Pernambuco, Caixas 136, 168, 169, 170, 171, 190, 193, 198, 201, 205 e 207; Rio de Janeiro, Caixas 7, 72, 96, 120, 129, 145, 147, 164, 165 e 191; Rio Negro, Caixas 7, 8 e 14; São Paulo, Caixa 18.

\section{NOTAS}

${ }^{1}$ A expressão "De farinha, bendito seja Deus, estamos por agora muito bem", que dá título ao artigo, foi extraída de ofício dirigido ao alferes Bento Coelho da Silva, comandante da Barra do Dande e regente do mesmo distrito. Arquivo Histórico Ultramarino, Conselho Ultramarino (doravante AHU), Angola, Códice 1630, fls. 107v-108. Quando referentes ao Brasil, os documentos do AHU foram consultados em: http://resgate.bn.br/docreader/docmulti.aspx?bib=resgate\&pagfis $=$.

${ }^{2}$ Cf. "Como um adoçante virou centro de uma batalha entre indígenas e multinacionais", 28 dez. 2016. Disponível em: http://www.bbc.com/portuguese/geral-38407924; Acesso em: 2 jan. 2017.

3 "Justiça livra a Natura da acusação de prática de biopirataria". O Estado de S. Paulo, 27 maio 2013. Disponível em: http://economia.estadao.com.br/noticias/geral,justica-livra-a-natura-da-acusacao-de-pratica-de-biopirataria,154800e; Acesso em: 3 jan. 2017.

${ }^{4}$ Que reconheceu a "estreita dependência de recursos biológicos de muitas comunidades locais e populações indígenas com estilos de vida tradicionais ... e que é desejável repartir equitativamente os benefícios derivados da utilização do conhecimento tradicional...". Decreto Legislativo $\mathrm{n}^{\circ}$ 2, de 1994. Disponível em: http://www.mma.gov.br/destaques/ item/7513; Acesso em: 3 jan. 2017.

${ }^{5}$ As citações nos parágrafos anteriores remetem a LÉRY, 1961, p.102-103; SOUSA, 1987, p.172-180; e GÂNDAVO, 1980, p.12-13.

${ }^{6}$ Ver também EDWARDS, 1847, p.39.

${ }^{7}$ Regressando de Cochim em 1559, essa nau enfrentou uma viagem desastrosa, na qual os tripulantes e passageiros, depois de escaparem de inimigos franceses em alto-mar, sobreviveram com parcas quantidades de alimentos: um pouco de vinho, "uns muito poucos punhados de farinha de pau”, alguma carne e peixe (RELAÇÃO do naufrágio..., 1942, p.32).

${ }^{8}$ A produção de farinha nos domínios lusos era insuficiente para saciar a fome da população residente e dos escravos transportados pelo tráfico. As remessas corriam o Atlântico, como pode ser exemplificado pela fragata $L u a n d a$, que saíra de Pernambuco em outubro 
de 1798 com destino a São Tomé e Príncipe e encontrava-se em Angola em janeiro de 1800 , carregando "farinhas de mandioca de que se tem por causa de esterilidade experimentado há três anos considerável falta neste reino...”. BNDM, 22,2,50.

${ }^{9}$ A proposta foi recusada, sendo o terreiro implantado sob a jurisdição do governador local e não da Câmara municipal, como acontecia no Reino e nos outros domínios ultramarinos. A situação era de conflito declarado entre as duas esferas de poder: o governador tinha certeza de que se o terreiro de farinha saísse de sua órbita seria "logo convertido em seminário de ladrões" e afastou diversos oficiais que ali trabalhavam "pelas muitas desordens que introduziam, com ruína e descrédito do mesmo estabelecimento...”. AHU, Angola, Caixa 48, doc. 48. Até o final da década de 1770, ao menos, a jurisdição do terreiro público de Luanda permaneceria nas mãos do governador, cf. AHU, Angola, Caixa 54, doc. 24 e Caixa 62, doc. 86.

10 "A penetração dos produtos americanos na dieta dos escravos, em particular a farinha de mandioca, reduziu os custos de frete para os portos do Brasil e de África e contribuiu para a adaptação dos africanos à escravatura luso-brasileira. Os produtos sul-americanos transplantados para África também reforçaram os produtos agrícolas locais e promoveram o aumento das incursões dos negreiros e caçadores de escravos. O acrescento do milho e da farinha de mandioca à dieta das tropas jagas possibilitou que estes grupos de caçadores alargassem as suas áreas de captura. A mandioca e o milho também foram cultivados por jesuítas e colonos nas plantações de Angola, no segundo quartel do século XVII" (ALENCASTRO, 2010, p.117-118 e 125).

${ }^{11}$ Como se queixou um capitão da Armada portuguesa em 1796, ao denunciar "a falta e careza de víveres em que esta terra [Bahia] se acha ... O governador diz que deu ... as providências para prover os navios de mantimentos ... mas ao presente não há farinha de guerra, não há carne, não há legumes, não há arroz...”. Arquivo Histórico da Marinha, Caixa 329, Pasta 7: Esquadras do Brasil, 1776-1825, doc. 329.

${ }^{12}$ Foi assim com a corveta São João Batista, que partiu do Rio em 1773 carregada de açúcar, secos e molhados, madeiras e um paiol de farinha de mandioca. AHU, Rio de Janeiro, Caixa 96, doc. 8273.

${ }^{13}$ AHU, Pernambuco, Caixa 168, docs. 11877, 11900 e 11906; Caixa 169, docs. 11962 e 11968; Caixa 170, docs. 11987, 11999, 12011, 12020 e Caixa 171, docs. 12037, 12043, 12050, 12077 e 12088. No Recife, os armazéns da Intendência da Marinha mantinham algum estoque de farinha de mandioca, certamente para abastecer os navios da Armada que por ali passavam. Arquivo Histórico da Marinha, Caixa 363, Pasta 67: Intendências da Marinha no Brasil - Pernambuco, 1798-1822.

${ }^{14}$ Representação dos produtores de farinha de mandioca das vilas de São Mateus e Caravelas ao príncipe regente, c.1807. AHU, Bahia, Caixa 248, doc. 17097. Arroz, milho e feijão responderam por $12 \%$ de todos os gêneros que entraram no Celeiro Público de Salvador entre 1785 e 1851; a farinha de mandioca representou os $88 \%$ restantes (cf. BARICKMAN, 2003, p.91 e 134-137). De outras capitanias também vinham explicações sobre a dificuldade em abastecer os navios destinados ao Reino com farinha de mandioca: AHU, Pernam- 
buco, Caixa 201, doc. 13760 e Caixa 205, doc. 14033; AHU, Maranhão, Caixa 102, doc. 8250 e Caixa 111, doc. 8664; AHU, Rio de Janeiro, Caixa 191, doc. 13736; AHU, Ceará, Caixa 15, doc. 865; AHU, São Paulo, Caixa 18, doc. 896; AHU, Maranhão, 2 de novembro de 1800, Caixa 113, doc. 8816 e Caixa 115, doc. 8929.

Artigo recebido em 17 de janeiro de 2017. Aprovado em 20 de fevereiro de 2017. 